\title{
Are Internet-Based Services More Sustainable?
}

\author{
Adi Wolfson ${ }^{1}$, Dorith Tavor ${ }^{2}$, Shlomo Mark ${ }^{3}$ \\ ${ }^{1}$ Green Processes Center, Sami Shamoon College of Engineering, Bialik 56. Beer Sheva, 84100, Israel \\ adiw@sce.ac.il \\ ${ }^{2}$ Green Processes Center, Sami Shamoon College of Engineering, Bialik 56. Beer Sheva, 84100, Israel
} dtavor@sce.ac.il

\author{
${ }^{3}$ Negev Monte Carlo Research Center (NMCRC), Sami Shamoon College of Engineering, Bialik/Basel Sts. Beer \\ Sheva, 84100, Israel
}

\section{marks@sce.ac.il}

\begin{abstract}
The Internet has affected a revolution in our behavior and communication as well as in how we perceive and implement services. It offers new opportunities, like the self-service mode, a service operated mainly by the customer, which enables the more efficient and conscious use of resources, technologies, and knowledge, and thus an opportunity to imbue the service with sustainability. Yet, such a move does not occur in a vacuum, and it demands a corresponding behavioral shift by both provider and customer, who have the shared responsibility to educate themselves about, and to monitor, the sustainability of the service(s) in which they are interested. As such, it is the provider's duty to supply a sustainable solution while the customer, who has obtained the information necessary to rate the alternatives, should choose the most sustainable one.
\end{abstract}

The power of internet-based services is not only in their availability and ease of operation, but also in the efficiency manifested in the customer's ability to perform several services together with virtually the same resources and effort. While these advantages can be easily superimposed on any design to ensure more sustainable services, the same properties may lead to increased, unsustainable consumerism.

\section{General Terms}

Service, Internet, Information, Sustainability

Indexing terms

Service science, service system, sustainability, sustainable service, Self service, Super-service.

\section{Academic Discipline And Sub-Disciplines}

Service science, Environmental Studies;

\section{SUBJECT CLASSIFICATION}

Service

\section{COVERAGE}

\section{TYPE (METHOD/APPROACH)}

Service science, information systems, carbon footprint

\section{Introduction}

Computer networks, and especially the Internet, have brought about a huge revolution in the way that we behave and interact [1], with the main changes expressed in the easy accessibility of information and knowledge and the growth and importance of global communication. However, this revolution has also provided myriad new opportunities to change our traditional consumption habits for a variety of products, both tangible and intangible, i.e., services [2].

Service is defined as value transfer from provider to customer to supply a solution required by the customer [3-5]. In recent years, during which the service sector has grown immeasurably with services becoming increasingly more complex and comprehensive, IBM defined a new track of research, service science, that focuses on the study of service design and value co-creation and that investigates new service opportunities, modes and technologies [6, 7].

One of the most important challenges the service sector faces today is to design more sustainable services that balance the needs of the present without compromising the ability of future generations to meet their own needs [8-10]. Sustainable service is primarily a solution based on environmental and social awareness, rational use of natural resources, and efficient operation of the service, i.e., a sustainable solution (Fig. 1). However, as each service also 
interacts with other services and manufacturing and agricultural processes, a sustainable service should be implemented such that the customer becomes a supplier of sustainability to the next generation.

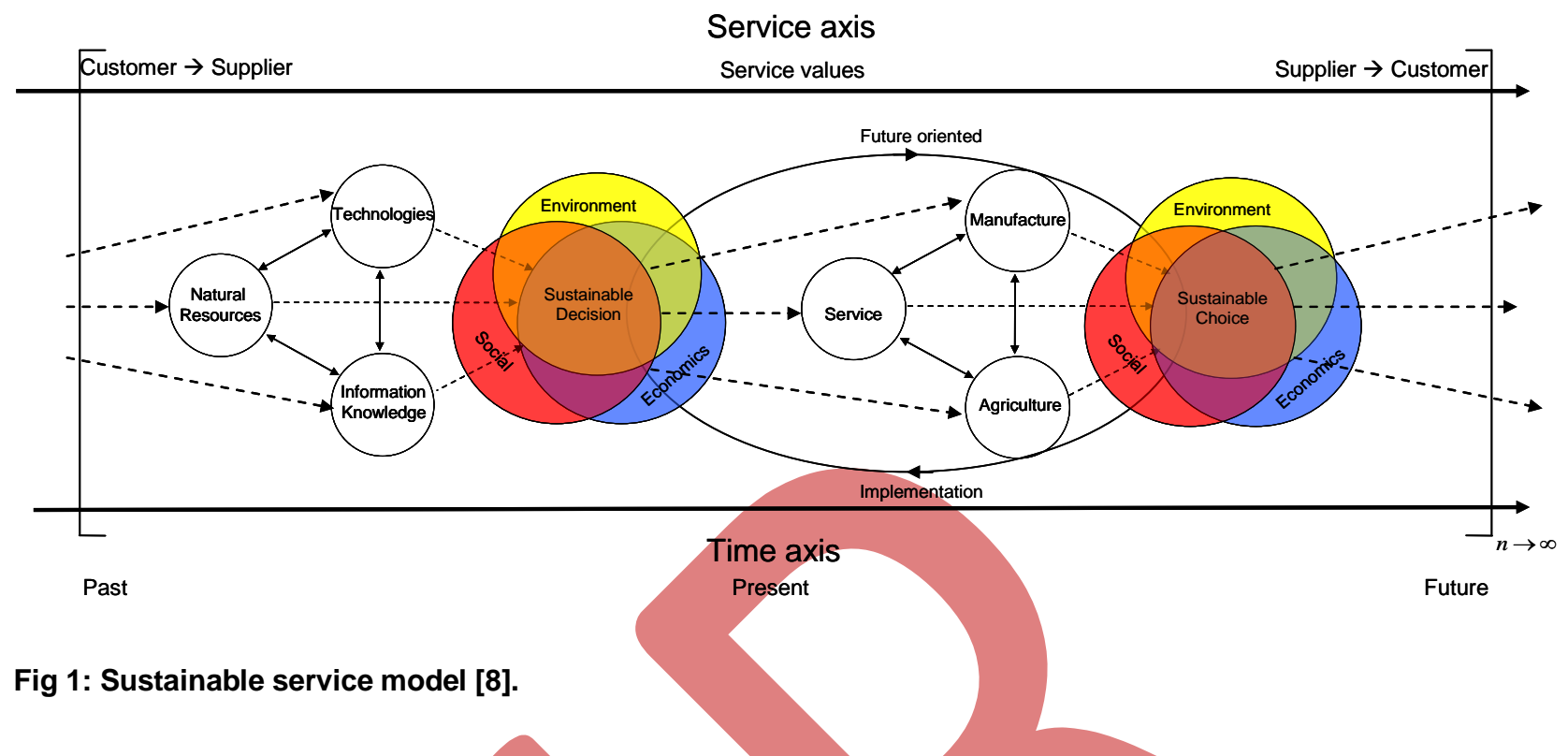

The Internet offers different alternatives for operating traditional services, such as reading, shopping, and advertising, which increases service flexibility and accessibility and changes the traditional distributions of resources used and effort invested between the service provider and the customer [11, 12]. As such, it necessarily uses natural resources, energy, and facilities, and it relies on different knowledge and technologies. Thus, that provides an ideal opportunity to design new, sustainable solutions for existing services and these new solutions typically involve new added value.

This study focuses on the relationships between internet-based services and sustainability and on the opportunities and restrictions that should be taken into account to ensure that internet-based services are imbued with sustainability.

\section{New internet service opportunities}

\subsection{Multi-channel services}

The main power of the Internet as a service platform is that it allows the simultaneous or tandem operation of multiple services, i.e., a series of services that are performed in parallel or in sequence, to form a service system. Since its creation, the Internet has offered a simple, flexible, low cost alternative to traditional service avenues together with complementary services, especially for information searches but also for mediating between services and managing and operating them.

Although most services function as stand-alone businesses, they also participate in service systems that operate in concert. In so doing they must exploit supporting services and cultivate interactions between services and different consumers to supply a value, e.g., a super-value, to the end user. Use of the platform supported by the Internet has enabled the faster, more efficient functioning of the service system, thereby lowering overall operational costs. In fact, there are almost no service providers today that do not use the Internet in some way as a supporting service in their supply chains.

For example, the traditional person-to-person service of hotel reservations provided by a travel agency is substituted today by various internet-based services, such as searching for the best hotel deals on the Web instead of calling a travel agent or the hotel directly or searching in brochures. The hotel reservation service has also evolved to use supporting services offered on the Internet to supply its core-value. Yet in the case of hotel reservation systems, the Internet has also added value in that it offers easily and rapidly accessible complementary services, such as providing maps of tourist destinations on which hotels, restaurants, and a wide range of other opportunities (e.g., arts and entertainment, historical sites) in and around the intended destination are clearly marked.

\subsection{New service modes}

As a globally interconnected network of smaller regional computer networks, the Internet also offers a platform for novel service modes. Although they can supply the same value as traditional person-to-person service routes, these new modes of service can also significantly reduce resource consumption and the human effort required for their operation. This translates into lower operational costs and less time invested to run the service. Moreover, in addition to increasing the service's overall efficiency, the adoption of this new service setup entails a redistribution between service provider and customer of these traditional measures-i.e., resource consumption, operational costs, and others-for evaluating services, thereby increasing the service's flexibility and accessibility, ([11, 12] Fig. 2). 

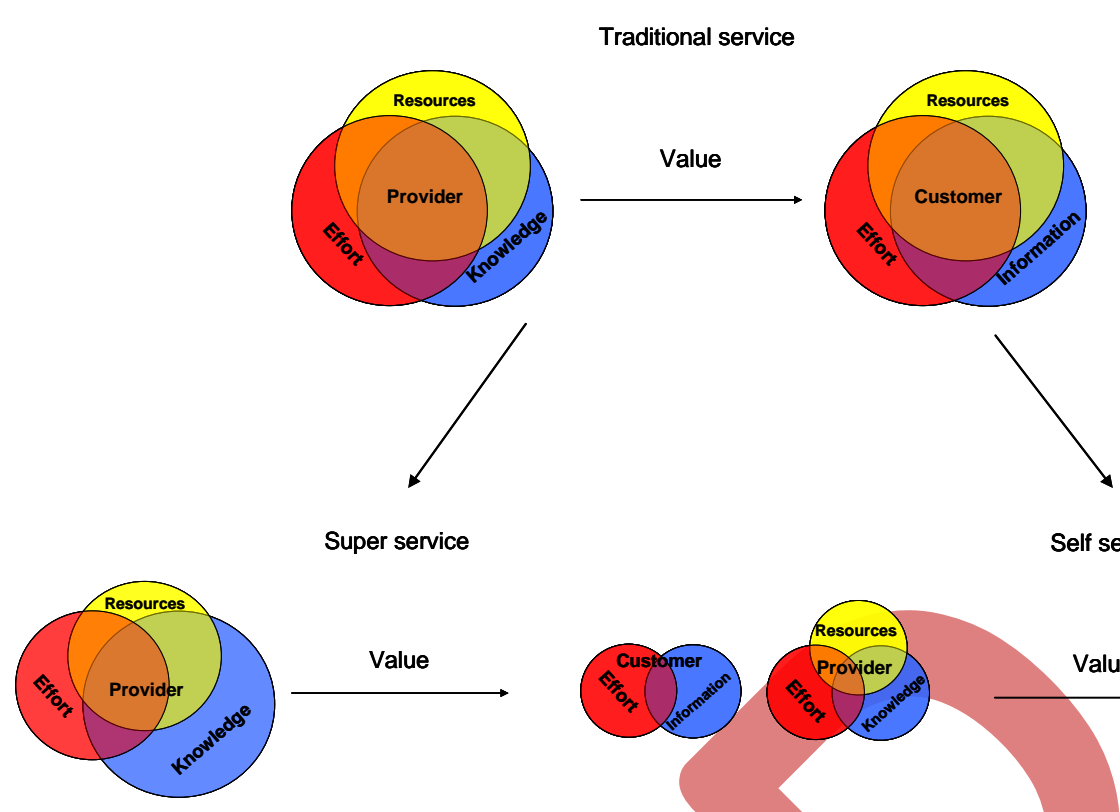

Self service

Fig 2: Different service modes.

\subsubsection{Self-service}

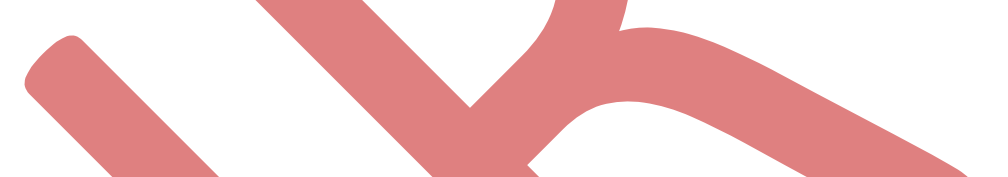

A service mode whose utilization has been tremendously accelerated by the Internet is that of the self-service, which refers to a service that is operated in full by the customer. The service provider, meanwhile, supplies the platform, e.g., the know-how, technologies, and facilities, the service needs to function. Because the Internet provides, for the most part, a user-friendly platform from which to operate a business [or part(s) of a business] that can be run as a self-service, and it is accessible 24 hours a day, many traditional services have been modified or otherwise redesigned to match the internet-based self-service model. Take, for example, internet-based bill payment systems whose operation entails a significant reduction in the facilities and manpower that the provider traditionally supplied and the corresponding effort that was required of the customer. Before the dawn of the Internet, the service provider was obliged to have employees in an office where the customer had to go periodically to pay his/her bills, which usually involved waiting in a line. Furthermore, an internet-based bills payment system considerably augments the service's flexibility, since it is usually available 24 hours a day, thus freeing the customer from the time and place constraints that defined the traditional service mode.

\subsubsection{Super-service}

Another service mode that has grown with the Internet is the super-service, the operation of which relies mostly on the supplier while the corresponding effort and resource investments required of the customer have been reduced significantly. Like self-service, the motivation behind the super-service is also the minimization of resources and effort on the part, in this case, of the customer. A good example of a super-service is a supermarket grocery delivery service, for which the service provider is responsible for the investment of all resources and effort, from boxes for packing the groceries to the mode of transportation to deliver the groceries to the customer, who can perform the entire transaction from the comfort of his/her home or office or in any number of places where an internet connection is available.

\section{Imbuing services with sustainability}

A sustainable service is that which can be maintained for long periods of time while having a minimum negative impact on human society and on the environment [8-10]. We recently published a novel rationale and model that describes sustainable service in a nature mimicry fashion and in two phases. The first step is the design of a core-value that imbues rational and efficient use of resources, technologies, and information and knowledge to offer a sustainable solution. The second step is to incorporate a super-value in the service by integrating it with other services and processes. In this step, both provider and customer strive to choose the most sustainable alternative for implementing the service, a choice that necessarily includes transferring sustainability to the next generation.

Taking the above-mentioned considerations into account, it seems that internet-based services are in general more sustainable than their traditional competitor as they usually consume fewer resources and require less effort. Moreover, as internet-based service offer easy integration with other services in creation of multi-service system, this communication between services can be used for designing sustainable super-value, and thus more sustainable solution. Nevertheless, it should be considered that replacing tradition parson-to-parson services by internet-based service is usually associated with cuts in manpower that could have negative social impacts. 
As illustrated in Fig. 1, a sustainable service is primarily based on a sustainable solution that accounts for the rational use of natural resources, clean and efficient technologies, and information and knowledge. Moreover, in the case of internet-based services, the balance between provider and customer of the investments in resources and effort needed to operate the service differs radically compared to the traditional service mode (Fig. 2). Because internet-based services are operated mainly as self services, the resources the supplier must provide in terms of materials, energy, manpower, and infrastructure are significantly lower when compared with the traditional service design. Furthermore, besides a suitable internet connection and the devices needed to access that connection, the customer does not need to invest in any special resources or infrastructure.

The new resources and effort map that characterizes internet-based service can be illustrated using the example of flight reservation systems by comparing the traditional person-to-person (PTP) service with its internet-based self-service (SES) incarnation, i.e., e-ticketing. Table 1, summarizes the split of resources and capabilities between the provider and the customer in both service modes, considering the service core-value (CV), i.e., ticket purchase, and super-value (SV), i.e. travel agency or computer operation.

Table 1: The split of resources and capabilities between customer and provider in traditional person to person (PTP) and self-service (SES) flight reservation.

\begin{tabular}{|c|c|c|c|c|c|}
\hline & \multirow{2}{*}{$\begin{array}{l}\text { Mode } \\
\text { Value }\end{array}$} & \multicolumn{2}{|l|}{ PTP } & \multicolumn{2}{|l|}{ SES } \\
\hline & & Provider & Customer & Provider & Customer \\
\hline \multirow[t]{2}{*}{ Resources } & CV & Paper, electricity & Non & Electricity & Electricity \\
\hline & SV & $\begin{array}{l}\text { Electricity, water, } \\
\text { furniture, } \\
\text { Manpower, ect. }\end{array}$ & Gasoline & $\begin{array}{l}\text { Electricity, water, } \\
\text { furniture, } \\
\text { Manpower, ect. }\end{array}$ & Non \\
\hline \multirow[t]{2}{*}{ Facilities } & CV & Travel agency & Non & Web site & Computer \\
\hline & SV & Central agency & Car & Central agency & Home/ \\
\hline \multirow[t]{2}{*}{ Effort } & CV & Manpower & Non & & Internet use \\
\hline & SV & $\begin{array}{l}\text { Central agency } \\
\text { operation }\end{array}$ & $\begin{array}{l}\text { Driving to the } \\
\text { agency, } \\
\text { standing in the } \\
\text { line , car } \\
\text { operation }\end{array}$ & $\begin{array}{l}\text { Central agency } \\
\text { operation }\end{array}$ & $\begin{array}{l}\text { Central } \\
\text { agency } \\
\text { operation }\end{array}$ \\
\hline \multirow[t]{2}{*}{ Knowledge } & CV & $\begin{array}{l}\text { Travel agency } \\
\text { system operation }\end{array}$ & Non & Non & Internet use \\
\hline & SV & $\begin{array}{l}\text { Central agency } \\
\text { operation }\end{array}$ & Car operation & $\begin{array}{l}\text { Central agency } \\
\text { operation }\end{array}$ & Non \\
\hline
\end{tabular}

Flight reservations, once performed by the customer through a travel agency, can today be done online from the customer's own computer using the self-service mode. Regarding resources and effort, in the case of the travel agency, the service provider has to maintain offices (often comprising a central office with several local branches) that require manpower and equipment (e.g., furniture, office equipment, and computers), and other resources such as electricity and water. In contrast, to operate the service, there is no demand on the customer to provide either facilities or equipment, but he/she typically exploits other resources, such as transportation to the agency's offices, the effort invested waiting in the line, etc. But that resources and effort map changes drastically when flights are booked directly by the customer over the Internet. In offering the customer the choice to make flight arrangements using the self-service mode, the supplier can reduce both its facilities and its manpower, in addition to other resources, as the service can be operated by a central agency. Likewise, the customer requires no special facilities to operate the service, since it can be accessed using the customer's personal computer, whether that be at home, in the customer's office, or (for customers living in urban environments) at any one of the widely available wireless network access points that are typically situated in central locations, such as university campuses, coffeehouses, and other public areas.

The customer's choice to use a company's self-service option to book flights, however, requires a greater investment in effort (i.e., time spent on the Internet) on the part of the customer, as he/she is the one who searches for the best ticket deal and eventually places the order. Arguably, the total time spent by the customer booking tickets online will be even greater than the time he/she would have spent making flight arrangements using the traditional service mode, which entails traveling to the agency, waiting in the line, and negotiating with the travel agent. But performing the service using the online self-service mode usually allows one to perform the procedure in parallel with other tasks, and, importantly, it does not require the customer to leave their home or office. Moreover, the service is accessible at any hour of the day and is not restricted to the agency's working hours. Again, in offering the self-service option, the provider, who mainly has to keep track of procedures and does not need to spend time with the customer, can invest less effort for the 
same value, which is supplying the customer with flight reservations. Thus, it can be easily seen that the internet-based self-service mode is generally more environmentally friendly than the traditional service as the former consumes fewer resources.

Table 2 illustrates a comparison of greenhouse gas emission, as a measure of sustainability, for the two above discussed scenarios, person to person (PTP) and self-service (SES) flight reservation. For the calculation it was considered that while the traveling agency is used only for the purpose of the service, the customer house is not account as facility for the purpose of the service. In addition, it was considered that in both scenarios the greenhouse emission of central agency operation is equal. As can be seen from the resultss in Table 2, the total carbon footprint of internet-based self-service is much lower than that of traditional person-to-person service, mainly as the traveling to the agency and back is avoided.

Table 2: Comparison of greenhouse gas emissions in traditional person to person (PTP) and self-service (SES) flight reservation.

\begin{tabular}{|l|l|l|l|}
\hline & Factor & PTP $\left(\mathrm{CO}_{2}\right)^{1}$ & SES $\left(\mathrm{CO}_{2}\right)^{2}$ \\
\hline Resources and facilities & $140 \mathrm{KgCO}_{2} / \mathrm{m}^{2} / \mathrm{year}^{3}$ & 7 & 0 \\
\hline Traveling & $0.25 \mathrm{KgCO}_{2} / \mathrm{Km}^{4}$ & 3750 & 0 \\
\hline Internet search & $1 \mathrm{gCO}_{2}^{5}$ & 0 & 15 \\
\hline Total & & 3757 & 15 \\
\hline
\end{tabular}

${ }^{1}$ Assumption: $25 \mathrm{~m}^{2}$ office, 15 min service, 5 simultaneous activities per time, $15 \mathrm{Km}$ traveling.

${ }^{2}$ Assumptions: 15 internet searches.

${ }^{3}$ Assumption: Type 3, typical office [13]. ${ }^{4}[14]$

${ }^{5}[15]$

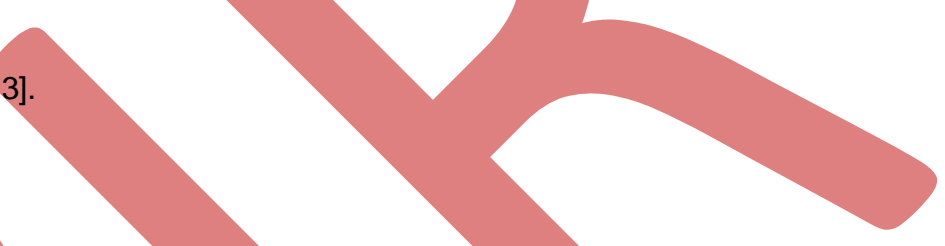

Considering the sustainability of services also necessitates examining the distribution between service provider and customer of the responsibility to imbue service with sustainability. In this respect it seems that besides supporting the savings in resources and effort associated with using super- or self-services, the Internet can also promote the sustainable operation of a service by offering new supporting services online that allow the service provider to increase the customer's awareness of sustainability and the customer to obtain the information and knowledge necessary to choose the most sustainable alternative and act accordingly. For example, carbon offsetting service that gives the customer the opportunity to compensate for his/her greenhouse gas emission during the flight by inventing in clean energy production or even by planting a tree. Table 3 illustrates an example of offset costs offer by Air France for various flights from Paris based on 20 $€$ per ton of emitted $\mathrm{CO}_{2}[16]$.

Table 3: Carbon offset of various flights from Paris.

\begin{tabular}{|l|l|l|}
\hline Destination & Distance (Km) & Payment $(\boldsymbol{\epsilon})$ \\
\hline Amsterdam & 906 & 1.92 \\
\hline Stockholm & 3498 & 7.42 \\
\hline Tel Aviv & 7452 & 15.82 \\
\hline New York & 12250 & 21.38 \\
\hline Beijing & 17204 & 27.82 \\
\hline Sao Palo & 19750 & 33.76 \\
\hline
\end{tabular}

Finally, it should also be taken into account that the ease, accessibility, and flexibility of internet-based services may also promote unsustainable consumerism. For example, the minimal effort required of the customer to shop online could promote an increase in the number of customers who purchase items they do not really need, which is perhaps a quality of distinctly human behavior that reflects just part of the complexity of imbuing services and processes with sustainability and of actually implementing the theory. It also implies that designing the core-value of a service to use alternative, more efficient technologies and even more rational resource consumption is not enough, and to actually deliver sustainability will require the careful formulation of a super-service. 


\section{Conclusions}

The market share of the service sector is constantly growing, and internet-based services are becoming the norm. The platforms supported by the Internet offer simple and highly accessible and flexible services that change the conventional division between the service provider and the customer in terms of the respective resources and effort each must invest to operate the services. Shifting the service boundary to a service that is mainly operated by the customer in the self-service mode is economically beneficial, as it entails automatic reductions in resource consumption and in the physical effort associated with operating the service. Furthermore, it provides an ideal opportunity to make services more sustainable.

The power of internet-based services is in the ability of the customer to perform multiple tasks while investing almost the same amount of resources and effort as required for a single task. These advantages can be easily realized in the conscious design and operation of more sustainable services, but one cannot neglect the potential that the pursuit of sustainability can also lead to increased and unsustainable consumerism.

\section{References}

[1] Okin, J. R 2005. The Internet revolution: the not-for-dummies guide to the history, technology, and use of the Internet, First Ironbound Press, 2005.

[2] Oliver, D., Livermore C. R., and Sudweeks, F. Self-Service in the Internet age, Springer, New York, 2009.

[3] Hefley, B., and Murphy, W. Service science, management and engineering: education for the 21st century, Springer, New York, 2008.

[4] Fitzsimmons, J. A., and Fitzsimmons, M. J. Service management: operations, strategy, and information technology, 5th Ed., McGraw-Hill, Boston, 2006.

[5] Brown, A.W., Delbaere, M., Eales, P., Johnston, S., and Weaver, R. Realizing service oriented solutions with the IBM rational software development platform. IBM System Journal, vol. 44, pp. 727-752, 2005.

[6] Maglio, P. P., Srinivasan, S., Kreulen, J., and Spohrer, J. C. Service systems, service scientists, SSME, and Innovation, Communications of the ACM, vol. 49, pp. 81-85, 2006.

[7] Maglio, P. P., Kieliszewski, C. A., and Spohrer, J. C. Handbook of service science, Springer New York, 2010.

[8] Wolfson, A., Tavor, D., Mark, S., Schermann, M., and Krcmar, H. S3-Sustainability and services science: novel perspective and challenge, Service Science, vol. 2, pp. 216-224, 2010.

[9] Wolfson, A., Tavor, D., Mark, S., Schermann, M., and Krcmar, H. Better Place: A case study of the reciprocal relations between sustainability and service. Service Science, vol. 3, pp. 172-181, 2010.

[10] Wolfson, A., Tavor, D., and Mark, S. Sustainable service: the natural mimicry approach. Journal of Service Science and Management, vol. 4, pp. 125-131, 2011.

[11] Glushko, R. J. Seven contexts for service system design. In: Maglio, P. P., Kieliszewski, C. A. , Spohrer J. C. (Eds.), Handbook of service science. Springer, New York, , pp. 219-248, 2010.

[12] Campbell, C. S., Maglio, P. P., and Davis, M. From self-service to super-service: how to shift the boundary between customer and provider. Information System and E-Business Management, vol. 9, pp. 173-191, 2011.

[13] Wade, J. Pett, J., and Ramsay, L. Energy efficiency in offices: assessing the situation, association for the conservation of energy, London, UK, 2003.

[14] http://www.carbonfootprint.com/calculator.aspx

[15] Gombiner, J. Carbon footprint of the Internet: consilience: The Journal of Sustainable Development, vol. 5, pp. 119124, 2011.

[16] http://corporate.airfrance.com/en/sustainable-development/co2-calculator/co2-calculator/ 